\title{
Practicing Design-Build
}

This relationship (computation) is disconnecting our profession from the feeling of swinging a hammer or driving a screw. Yet we face a true challenge where the computer is not only necessary in the digital age we find ourselves living but used correctly it is a true asset. We must begin to train our students and professionals how to design in digital space without losing sight of gravity, structure, assembly processes or materiality. The studio explored a series of relationships; research to practice, academia to the profession, design to materiality + prototyping and digital to physical environments. The exploration of these relationships destroyed the students understanding of what each relationship was and rebuilt their perception of each relationship.

MATTHEW GINES

University of New Mexico

\begin{abstract}
The disconnect from academia to practice from design to construction is carrying the Architecture profession out to sea. Students and young professionals are further disconnected from the reality behind the representation of each line. This paper discusses a studio structured to mimic the professional environment while at the same researching through prototyping pre-fabrication, modular building, DfD (Design for Disassembly), and panelization theory including on-site/off-site construction methods. This body of applied research proves student's abilities to design are dramatically increased through hands-on experience. They suddenly understand the implications of each connection, detail and callout on their drawings. The studio operates under the auspice of two divisions within a single firm, collaborating and working independently when appropriate. The studio mimics firms by "hiring" Project Managers, Construction Supervisors, Digi-Fab Specialists, Design Presentation, Materiality and Donation Teams/Groups. This paper demonstrates the process for collaboration and cross-pollination for two simultaneous design-build projects. This paper will prove that through building in multiple mediums students not only blur the disconnect from academia to practice but also from design to fabrication and construction. One of those methods is simulative modeling, which cannot be comprised of lines that represent parts; it however must be crafted by elements and assemblies of parts. Simulation modeling creates the opportunity for architects to develop a case-bycase kit of parts.
\end{abstract}

The studio examined conditions of architecture and the potential of how design and construction synergies will influence building typologies in the next century. Building 
upon the skills and knowledge developed from the master builder, the studio investigates architectural conditions by incorporating traditional making, digital fabrication and the computer as design tools. If we as architects intend to use technology to become true 21st century "master builders" we must understand that the term entails a very different set of parameters than it did 500 years ago. The investigation becomes a fluid integration into constructed principles. To achieve these goals and give students the experience of trade a series of workshops are taught including specific instruction for software and hardware which proved instrumental in materiality, connection and other important design decisions.

Suddenly when the responsibility of the product literally fell in the hands of the students their awareness and design decision making was heightened, improved and pushed in order negotiate cost, design and feasibility of fabrication and construction. This research has proven the void from education to practice is experience, or hands on experience. We are losing our profession to a digital age of slowly eliminating the relationship of the Architect to building. This is apparent through the introduction of BIM, where instead of drawing lines, information is entered through (some) spreadsheet data. This design-build studio serves as a driver for theoretical, experimental and abstract conditions that not only manipulate the way buildings are made but allows a master builder of the digital era to emerge in the 21st century. Without a drastic change in the way architecture addresses the experience and understanding of how we build we will ultimately drive our own obsolescence as a profession and as a society.

A single disconnect from Academia to practice would suggest an easy solution to our detachment could be found by simply putting our heads together. Rather than a single intersection, many disconnects between Academia, practice and the disciplines of architecture, construction, fabrication and design exist and these severed relationships are destroying the ability we once had to produce beautiful architecture. As the Architect continually moves away from the idea of the Master Builder model we distance ourselves further from the knowledge and understanding that once founded our ability as experts in buildings. Architects once knew what the representation of lines on paper and the real-world implications of drawings meant to a craftsman. As designers continue to spend more time in front of their screens they become further disconnected with how the digital world becomes the physical. This relationship (computation) is disconnecting our profession from the feeling of swinging a hammer or driving a screw. Yet we face a true challenge where the computer is not only necessary in the digital age we find ourselves living but used correctly it is a true asset. We must begin to train our students and professionals how to design in digital space without losing sight of gravity, structure, assembly processes or materiality. The studio explored a series of relationships; research to practice, academia to the profession, design to materiality + prototyping and digital to physical environments. The exploration of these relationships destroyed the students understanding of what each relationship was and rebuilt their perception of each relationship.

\section{RESEARCH TO PRACTICE}

In the academic environment research is easily achieved through assignment based learning. This is not always true of the profession; budgets and deadlines often prevent time spent investigating or prototyping new ideas. Academia is training students to produce great work however it is not training them to work in groups or teams on projects. Although it is much easier to track each student's exact efforts when work is individual, this imbeds a culture of professionals who don't work well together. This trend created by Academia has to be changed, when students are asked to work together in 

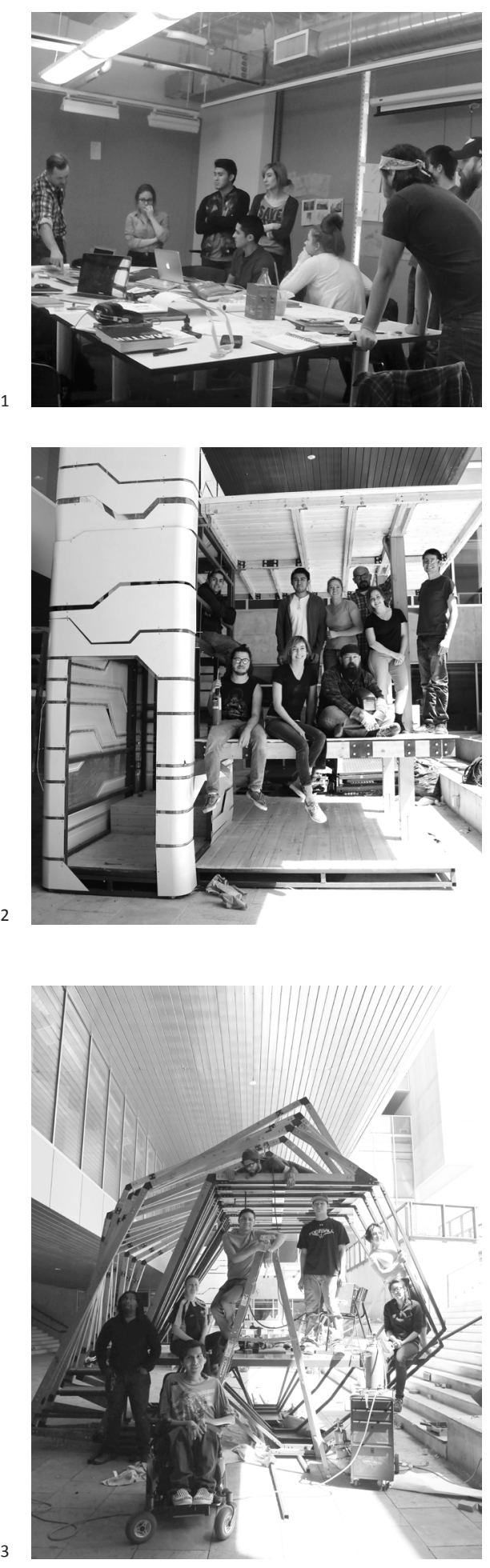

Figure 1: Collaborative Studio

Figure 2: Toy Factory Team

Figure 3: Fairytale Team teams they ultimately struggle with the hierarchical order which manifests in personality conflicts. This studio attempted to diminish the idea that any one singular person was responsible for any one singular design aspect. In order to test these two theories students never worked individually and the timeline for research on a team project was cut in half of what it should typically take. In the case of their first assignment they were given three weeks to produce a body of research that should normally take six weeks.

In teams students were asked to develop a body of research investigating Design for Disassembly (DfD), Design for Environment (DfE), Pre-Fabrication, Panelization, OffSite Construction, Mass Customization, Mass Production, Construction and the Means of Production, Modularity, Transportability, and off-the-shelf components. (They were to choose a minimum of 3 from the list) This research focused on invention, materiality, methods of assembly vs. construction, prototyping, fabrication, precedent analysis, historical explorations, theoretical discourse, digital building, physical model making and experimentation. The assignment challenged the students to reframe how they perceive architecture and the way research is conducted through making, including craftsmanship, and ideas of the master-builder ideologies. They were challenge to re-claim responsibility and through the process of design become 21 st century master-builders. Specifically this referred to the digital era of architecture and a renewed role including partnerships with computer driven machines and technology providing increased opportunities for the designer to take more responsibility in every aspect of architecture from design to construction and eventual remodeling or demolition. The intent of the condensed research was to inform the Thesis for their work throughout the semester. By considering how Architecture is designed, built and delivered to a site through both form and function, this research served as the driver for cohesive technology and design of objects, spaces, aesthetics, materialization and fabrication of a Design-Build project.

\section{ACADEMIA TO PROFESSION}

In order to bridge the disconnect from an Academic studio to a professional environment the class was structured to mimic a professional firm. The studio instructor acted as the principal architect rather than an instructor. They key difference is that the students are expected to already know how to produce the necessary documents, drawings, renderings rather than nurturing along the progression of their individual building project. The studio environment this created was very similar to a young firm just getting started. The first project acted as an extended interview within the firm where the principal could oversee and consider students for more advanced roles in the coming weeks of the studio. By the end of the first assignment ( 3 weeks) very few of the students were able to understand the research was to be rooted in the real world, or that the objects they were prototyping should be directly applicable to buildings, a disconnect often created by academia. Students are trained throughout their academic career to "research" by 3-d modeling and rendering or building small models from materials not feasible in the built environment, this causes a residual reaction when students respond to an assignment in which they do not treat the "research" as real world objects. Though the majority of final products and prototypes from the first assignment were inspiring and often amazing the studio had to spend time working an additional week on translating one or more of their projects to a more realistic output. Often times a studio would simply extend a project and postpone the next, however an office does not have that luxury and in this case the academic studio did not consider that as a possibility. The studio immediately began assignment two while assignment one was still wrapping up. Similar to the function of an office, many projects are often in process simultaneously in differing stages of completion.

The students responded well and within a week they had the first assignment off their 
plates in order to focus their attention on the design of two two-story playhouses. At week three of the semester the academic environment took a huge leap toward the professional setting. The studio was split in half with eight team members on each side, one Design-Team manager and one Construction Manager were assigned to each group. This "vertical" studio was structured with students from all three of the UNM School of Architecture and Planning's academic tracks in the Architecture program; our final semester BA Architecture, second semester March II and third semester March I students. This varied level of education and experience offered a parallel to the office setting where employees are in various stages of their careers. This type of setting provides an opportunity for more shared learning and respect of others experiences and knowledge. The project and construction manager assignments offered an immediate hierarchy in the studio structure with each design team manager organizing and leading their team in design exercises and delegating duties to subgroups. As the principal of the firm in this studio setting I met with my team managers during each studio to address any concerns or questions and spent the remainder of my time split between the two groups offering insight and allowing them to consider it as a team. The students desire to have ownership of the final design was obvious from the onset despite the direction for them to work in a team setting. The first few rounds of design were clearly a result of individual pieces tacked on from a few people resulting in forms that were less that attractive. As the principal of the firm I tried several methods of breaking down the barrier of selfownership in the project with an attempt to get them to understand the importance of the collaborative environment. This was accomplished first through design charrettes with the entire studio working on a singular project. This method was successful in defining the broad concept for each of the projects but lacked the ability to move forward with such a large group. A second attempt broke each group in to subgroups that worked independently and returned to the larger group to critique the collective ideas. The final method used for distilling the original form was for these subgroups to put all of their designs through a blind review with the entire group. This removed any issues with personality conflicts or the like and the entire group was able to select the best form to work from. Once the form was selected the groups finally began to work collaboratively. This blind process helped them understand importance and impact of collaborative design. The teams of eight finally, in the eleventh hour began to work as a unit and focused their design iterations as a collaborative group. They worked with each member present critiquing the 3-D modeling in real time. One person 3-D modeled throughout the discussion and work session (a 10 hour session) of the form and design allowing the design process to flow seamlessly by working in a collaborative environment. The design phase of the design-build project finished with a client presentation and approval to proceed with the project as demonstrated. The two teams began two weeks of documentation. Several participants from each team were selected to work on a publication while the other four remaining team members produced the construction document set for the build.

The construction document phase of the studio is not as simple as translating the design decisions on to a conventional format. This studio proved that many of the decisions necessary to build are not thought of at all in the academic setting. The construction document phase included the design and re-design of serval aspects of the projects including curtain walls, structure, lateral bracing, operable windows and many other elements that were claimed in the presentation to the client. Much of those concepts were much harder to achieve in the detailing than any of the students realized. Each of the design-build teams called on vendors for their material expertise for suggestions on how to best detail the attachment or selection of various materials. 

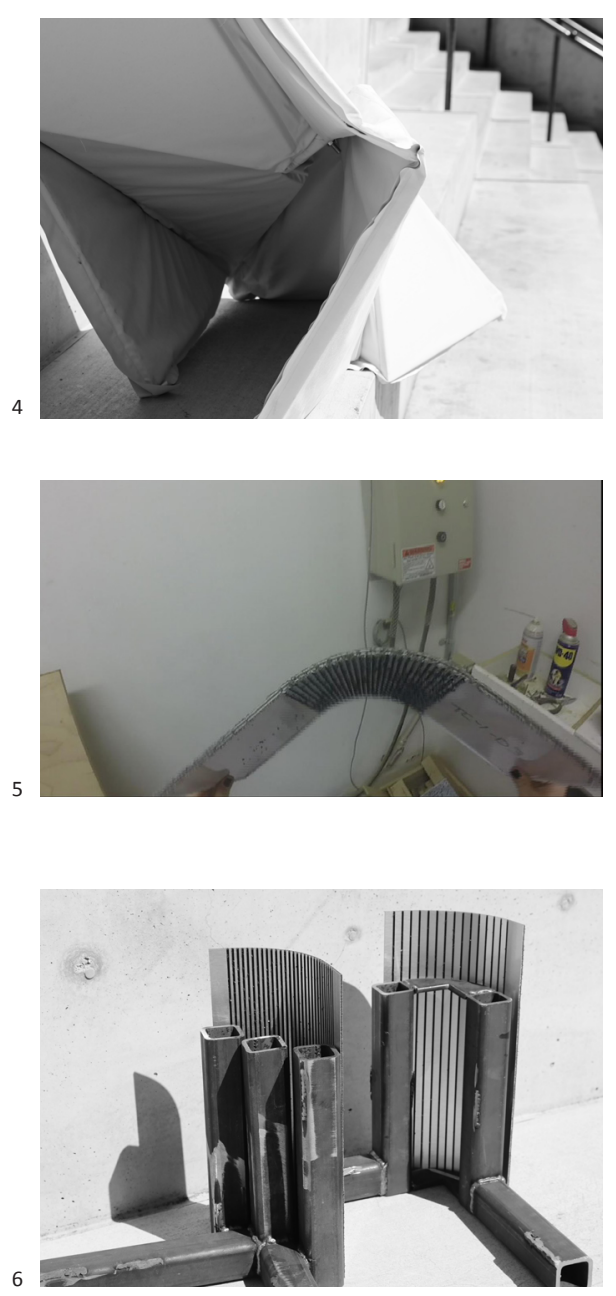

7

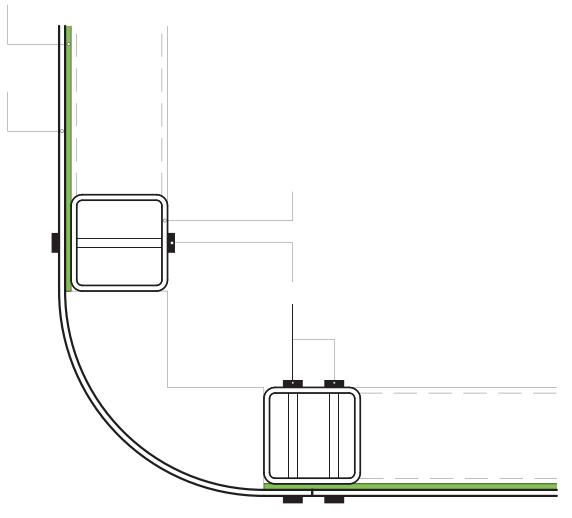

Figure 4: Fabric Testing

Figure 5: E-Panel CNC cutting

Figure 6: Steel + E-Panel Mock-Up

Figure 7: Final E-Panel + Steel Drawing

\section{MATERIALITY + PROTOTYPING}

The students demonstrated a strong desire to use some materials that required custom detailing. In particular one team designed their curtain walls with a custom CNC milled zinc skin. This required several meetings with the distributor to discuss the various options with zinc including finishes and application. In order to discuss these detailing options the Studio Instructor brought in the rep to look at the detailing of the zinc panels. The distributor presented several methods of attachment, flat application without seams, lock style with seams, and wrapping with rear mounted clips. Through the discussion the team was beginning to discuss using a taping method and they were close to solidifying that decision when we began to discuss how those panels needed to be able to be assembled, disassembled and moved to site where they would be reassembled. The realization of material weight, application method, permanence, and durability led them to a wrapping technique with a rear mounted clip system. This solution allowed the team to quickly demount the skin from the curtain wall for safe transport multiple times.

Both teams sought help from experts on specific material selections. In two specific cases the designers struggled with cedar vs. redwood and polycarbonate vs. acrylic. The experts offered their insight in material properties, durability, sun exposure, availability and cost. The experts also disproved old notions of polycarbonate as a better solution for strength and durability. The reps explained that today's formula for acrylic far surpass the former yellowing and brittleness from sun exposure that once took place. These factors made it easy for the teams to select cedar and acrylic for their final materials based on the information the material reps provided them. In this situation the students accepted the expertise readily and were amendable to the changes these selections made to their perception of the aesthetics.

One team struggled with an aesthetic decision in which they wanted to achieve a curved corner condition using an e-panel material. In order to investigate the corner condition as both straight and curved and the team used simulative modeling as an exploration tool prior to prototyping. By 3-D modeling the conditions they were able to collectively discuss the aesthetic implication of the detailing. The team finally worked well as a unit when they were attempting to find a balance between the obvious easy solution consisting of straight corners versus the aesthetic curve they preferred. Due to their desire to keep the aesthetic curved condition they began researching through prototyping. The team first did a series of back cuts, or scores in the e-panel to see how the scores read on the exterior surface and what degree of curve was possible. Through iterative prototyping the team CNC milled and testes the e-panel achieving their desired level of curve articulation with $1 / 8$ " wide scores with a $1 / 8$ " spacing. This demonstrates the need in architecture for designers to have the ability to physically prototype their ideas in order to prove or disprove concepts. In this case the prototype was then translated directly to the construction documents for final fabrication. Due to the resolution of the detail prior to making their final decision the team had no issues with the parts or pieces in final assembly. This example is where Academia and practice diverge in their ability to conduct research. In academia we are able to produce these type of prototypical conditions in a matter of hours, whereas in the professional setting we would need to hire a fabrication to produce something as a test resulting in a dramatic loss of time and expense. This setting, where the vast majority of practices do not have appropriate model shop space, tools, or access to fabrication of equipment, including laser cutters, or 3-D printers is at best an antiquated approach. Practicing firms find themselves unable to stay in-tune with academia due to the advances in technology because they are ignorant of the impact technology has in the profession. Academia is training students to be experts in technology with respect to digital modeling, 3-d printing, cnc machines, and robotics, while the majority of the profession is so far removed from technology the talent and 
training students received is not valued or used. This disconnect is slowing the professions use of technology and ability to conduct research within practice to a staggering halt.

\section{DIGITAL TO PHYSICAL}

While we teach students amazing technology and computational tools, academia does not show them how to translate ideas from digital concept to physical form. Academia often finds itself on the far side of the design thinking edge where beautiful renderings occupy unrealistic landscapes and structure is unheard of. This realm of academia where we go to play with design ideas unconstrained from any real forces is not simply unrealistic it is detrimental to the education of true designers who go on to work as architects. Academia must strike a balance between teaching how to use technology to produce exceptional built work. We can accomplish this through design-build situations of many scales where students are responsible for all aspects of the projects. This requires a constant dialogue between computer and physical object. This is where Academia should thrive, however technology and the digital image has watered down Academic pursuit to make objects that represent buildings, prototypes or the physical exploration of ideas. The relationship from the digital to physical in Architecture would be much more successful if students were required to me more iterative with their designs, that is; $3-d$ model to physical object, back to $3-d$ model resulting in a much better final product. Due to the relationship of the digital model the relationship to actual materials have become fractured and the rendered image carries the design regardless of its true potential as a realistic object.

"The concept of the craftsperson is so far removed from the architectural profession, which is staggering considering we have an abundance of new fabrication technology available to us to make. The idea of craft is integral to my love of the work. I no longer want to only occupy the purely heady design realm of conceptual ideas, drawings and models, but want to balance the conceptual with the physical. The realm of the body is important, and an experience many architecture students lack. How we touch and shape materials grounds us and empowers us within the physical world, and is a lesson I have been grateful to learn this semester. My future career choices will be profoundly shaped by the lesson of the craft, and has reinvigorated my love of design."

\section{-Arch 402 Design-Build Student}

This studio setting worked through digital modeling in order to create and test their prototypes resulting in design decisions through the process. The teams worked in a variety of mediums as appropriate including software, sketch, diagram and prototyping used as design tools during the collaborative process.

The disconnects between academia, practice, design and construction will soon require an overhaul in order for our industry to evolve in to something more recognizable as cohesive practice. Often, the office environment does not provide opportunities for creativity and likewise, the academic setting does not ground design in reality. As the digital age moves technology further forward, architecture falls behind and further disconnected from the reality behind the representation of each line and translation from digital environment to physical construct. This studio attempted to bridge that gap by mimicking the professional environment while maintaining the freedom of academia. This blend of academic and professional work provided a experience where prototyping pre-fabrication, modular building, DfD (Design for Disassembly), and panelization theory including on-site/off-site construction methods were explored with rigor and realism. The body of work created by this combined studio (4th year undergrad, 1st year MArch II, 2nd year MArch III) proves students abilities to design are dramatically increased through hands-on experience. Although this method of teaching in a collaborative setting is much
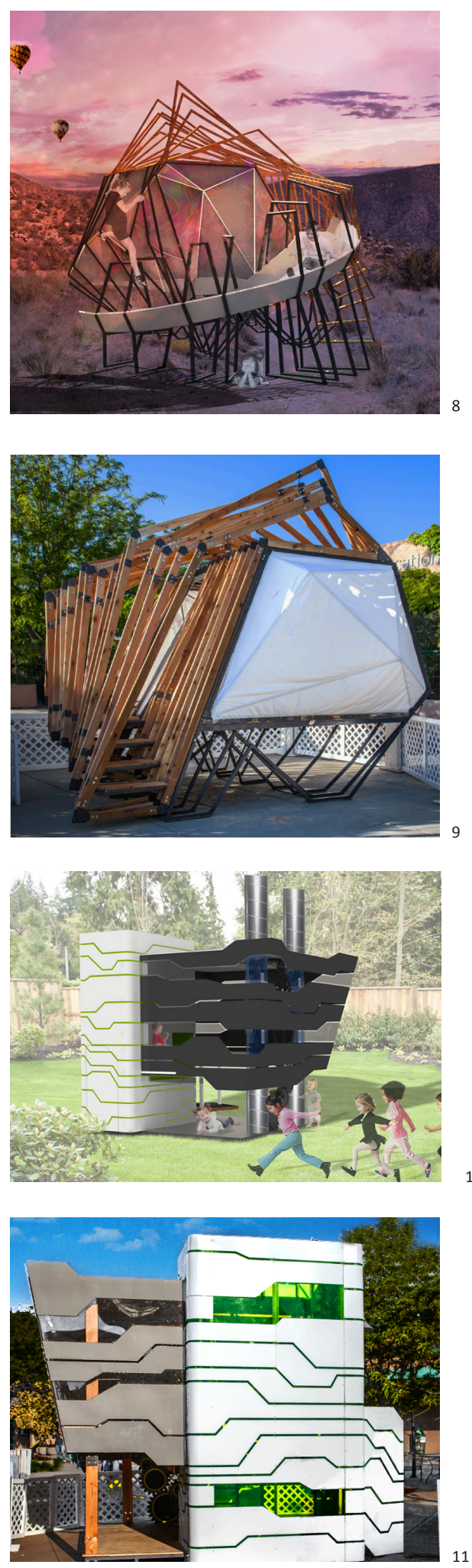

Figure 8: Fairytale Rendering

Figure 9: Fairytale Fabrication

Figure 10: Toy Factory Rendering

Figure 11: Toy Factory Fabrication 

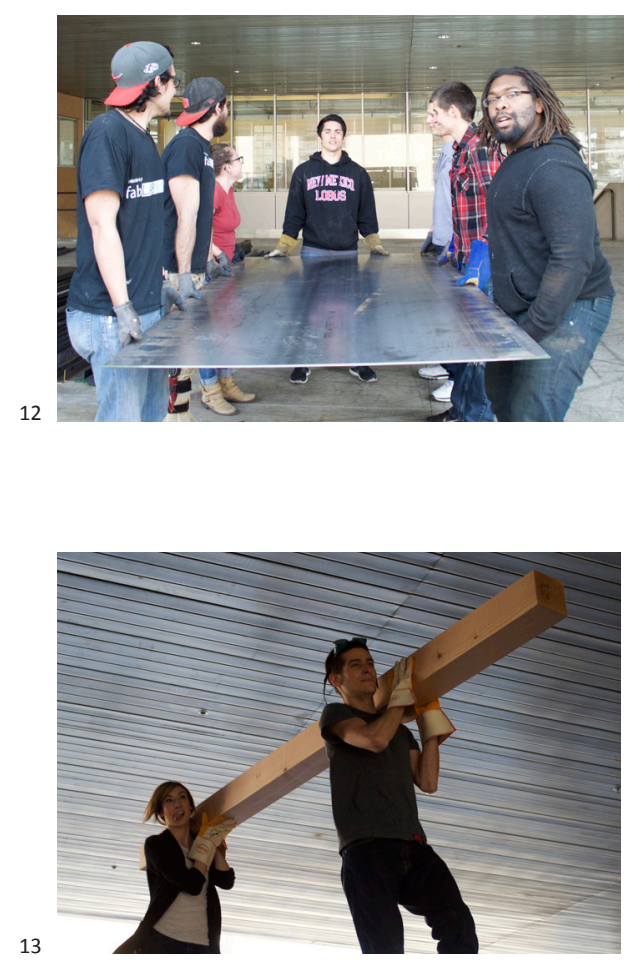

14

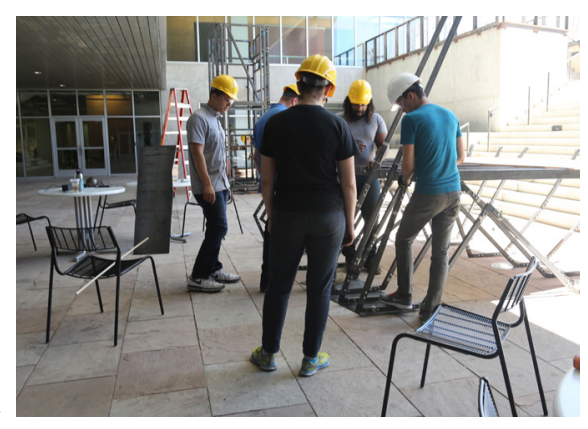

15

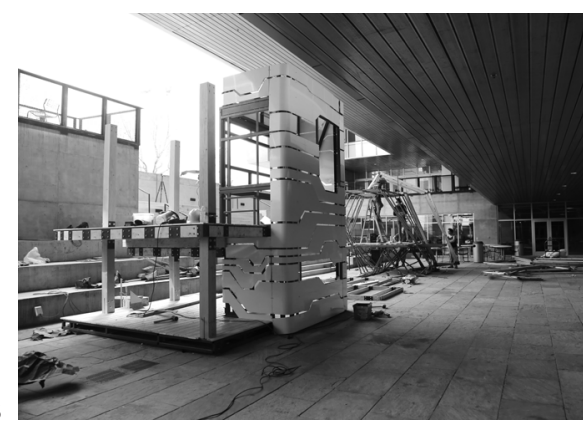

more difficult for the instructor, it is tremendously more rewarding for the students and the projects that arise from the endeavor. As the studio progressed through the semester the students understanding of what it takes to build buildings developed at an astounding rate. When forced to think through and apply the ideas and use their own drawings the result was palpable. One could see the transformation of the students on a daily basis, though they were not always aware it was occurring. In order for them to truly recognize what took place over the semester they were asked to reflect on their work, something Architects do not always have time for or do well.

\section{REFLECTION}

The only individual assignment done in the semester required the students to spend one week reflecting on their work. They were asked to reflect in two parts; Part 1: Select one construction method, fabrication technique, modelling/document method, or the re-design of a material choice/connection to redesign and detail. Analyzing the older condition create a comparison of the new to the former in a graphic representation. You will produce a construction document drawing(s), rendering(s) and photograph(s) of the existing condition as part of your comparison. Part 2: Reflection and Self Criticism throughout your career will help you to evolve as the best Architect/Designer you can be. Architecture should always be committed to the expansion of the research culture and supporting infrastructure in all the design disciplines. This type of work challenges many of the notions of how architects/designers should work, you have broken those "standards" and it has made an impact on you. Write a one-half to one page (no more than a page) reflection on our experience. Approach it from several viewpoints; 1 . Studio Structure, 2. Reflect on your Team experience, 3. Reflect on your individual experience, 4. discuss the short term and long term impact of the Design-Build studio has had on you (talk about it's impact on your design ability)

The reflection of the studio resulted in their understanding and realization of how far they had come. The students each spoke about their understanding of assembly, connections and materials in a much more profound way. They recognized the point at which they broke away a purely conceptual standpoint to realistic design principles that are buildable. The students understood the relationship from the conceptual realm and where it fits within the design process, and how those ideas became clearer when placed into physical practice. The clarity achieved by the studio was evident through the activity of building and it proves the Design-Build setting in education bridges many of the disconnects we face in Architecture and Design.

The second part of the reflection allowed the students to address issues that arose during or after the fabrication was complete. Students redesigned things like connections where it was difficult to fit your hand or the method of structuring the playhouses. This provided an outlet and experience for them to fully offer solutions to the mistakes made during the process. The redisgn process demonstrated to the students the need for exploring and researching through making. The Architecture and design profession has lost sight of applied research through making and building. The design-build projects in an education setting is successful at bridging the disconnect from education to practice to construction and will foster stronger and wiser Architects

Figure 12: Teamowrk

Figure 13:Material Handeling

Figure 14: Working Together

Figure 15: Assembly Progress 